TAS Journal, vol. 5, n. 1, p. 01-12

ISSN: 2595-1521

MARCH 2021

eduardobock@gmail.com

\title{
Fifteen years of the first Brazilian Centrifugal Ventricular Assist Device for long term Mechanically Assisted Circulatory Support
}

\author{
Bock $\mathrm{E}^{\dagger}$ \\ $\dagger$ Laboratory of Bioengineering and Biomaterials, Instituto Federal de São Paulo, Brazil.
}

\begin{abstract}
More than simply being a review paper and telling the story of the development of a ventricular assist device, this paper aims to critically review changes in technical nomenclature and scientific positioning, taxonomy and its applications, therapeutic indications and the results of its application in patients. After 15 years of the first Brazilian Centrifugal Ventricular Assist Device, many things have changed for the better. Mechanically Assisted Circulatory Support is a therapy consolidated as a safe and effective alternative for the treatment of congestive heart failure, as well as heart transplantation and other drug therapies. It is still seen as science fiction in several countries or media, but that is a cruel reality in our post-truth and fake news times. In reality, it should receive more funding resources especially in developing countries and emerging economies with strong hospital industry of the cardiovascular field that may have surprising results with all the technology already established.
\end{abstract}

Keywords. Centrifugal Ventricular Assist Devices, critical review, Mechanically Assisted Circulatory Support, Continuous Flow Ventricular Assist Device CFVAD.

Introduction. In order to start describing this first-person review, something not very common in the field of engineering or medicine, I need to go back a little over 15 years. More precisely, I will need to go back 20 years in this review to give an overview of Ventricular Assist Devices (VADs) research at the beginning of the 20th century. At that time, ending Engineering graduation, I decided to study with Prof. Jeison Fonseca at USJT joining the group of Institute "Dante Pazzanese" of Cardiology (IDPC), lead by Prof. Aron Andrade in Sao Paulo, Brazil. IDPC is a teaching, research and public health care institute that has always been at the forefront technological development of medical equipment, prostheses and surgical techniques related to cardiology. Prof. Aron Andrade studied with Prof. Yukihiko Nosé, a pioneer of artificial organs together with Prof. Adrian Kantrowitz. Nosé et al. (1963) were always ahead of their time (1) as one of the main paradigm breakers, developing the centrifugal Gyro Pump as VAD while the market was dominated by pulsatile pumps Novacor, Thoratec and HeartMate (2). Centrifugal blood pumps are just for Extracorporeal Circulation. To better understand the extension of his research, at that time, he was already comparing the design philosophy and strategy behind the three generations of VAD, since the pulsatile of the 60 s that he followed the birth (1) until the 
appearance of Continuous Flow Ventricular Assist Devices (CFVAD), from the first DeBakeyVAD axial pump, to the first Gyro-Pump Implantable Centrifugal pump (3).

As can be seen in Table 1, the first barrier to be broken was the implantability. While the pulsatile devices were large and heavy, often with actuators impossible to be implanted, the CFVADs brought the miniaturization of the devices and said goodbye to the pulsatility. Even today, after thousands of patients benefited from the assistance of CFVADs, as we will show, we still find supporters of pulsatile devices.

Table 1. Blood pumps general characteristics at 00's and the revolution of continuous flow ventricular assist devices (Nosé, 1998).

\begin{tabular}{cccc} 
& $\begin{array}{c}\text { Priming } \\
\text { volume [ml] }\end{array}$ & $\begin{array}{c}\text { Rotation or } \\
\text { Speed }\end{array}$ & Actuators \\
\hline Pulsatile VAD & $>60$ & 150 & Electromechanical \\
Centrifugal & $<25$ & 2,000 & Electromagnetic \\
Axial & $<5$ & 10,000 & Electromagnetic \\
\hline
\end{tabular}

Novacor considered long-term support the use of 1,000 days by a 54-year-old man patient (4). Researchers studying the HeartMate device, on the other hand, were proposing its use as bridge to heart transplantation (5)(6). Thoratec was already publishing results for 213 patients divided into: group $1(\mathrm{n}=74) \mathrm{LVAD}$; group $2(\mathrm{n}=37)$ patients initially receiving an LVAD and later requiring an RVAD; and group $3(\mathrm{n}=102)$ BiVentricular assistance (BiVAD) from the beginning (7). The main application was precisely the bridge for transplantation and a major scientific and technological challenge was to control infections (8). Table 2 shows the differences in size and implantability of two pulsatile devices and one CFVAD, Gyro-Pump (2).

Table 1. Comparison between Novacor, HeartMate VE (Pulsatile VADs) and Gyro PI 700 (CFVAD) sizes and weights (2).

\begin{tabular}{cccc} 
& Novacor & HeartMate & Gyro \\
\hline Height [mm] & 65 & 40 & 53 \\
Width [mm] & 130 & 112 & 65 \\
Length [mm] & 160 & 112 & 65 \\
Weight [g] & 860 & 1,193 & 465 \\
\hline
\end{tabular}

(Adapted from Yoshikawa, M. et al., 2000).

This was the reality when I started at IDPC in 2002 to work with the Auxiliary Total Artificial Heart (ATAH) project. Due to its constructive characteristics, with an electromechanical actuator 
TAS Journal, vol. 5, n. 1, p. 01-12

ISSN: 2595-1521

MARCH 2021

eduardobock@gmail.com

in the center, alternating the rotation of screws that push diaphragm propelling plates, the ATAH can be used as Total Artificial Heart (TAH) or VAD (9). Research team and animal experiments can be seen in Figure 1.

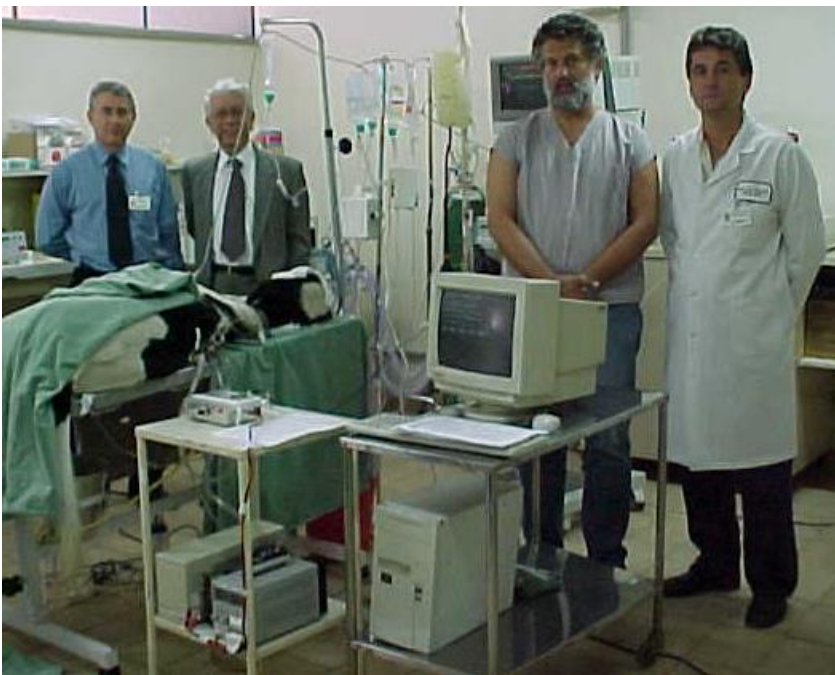

(a)

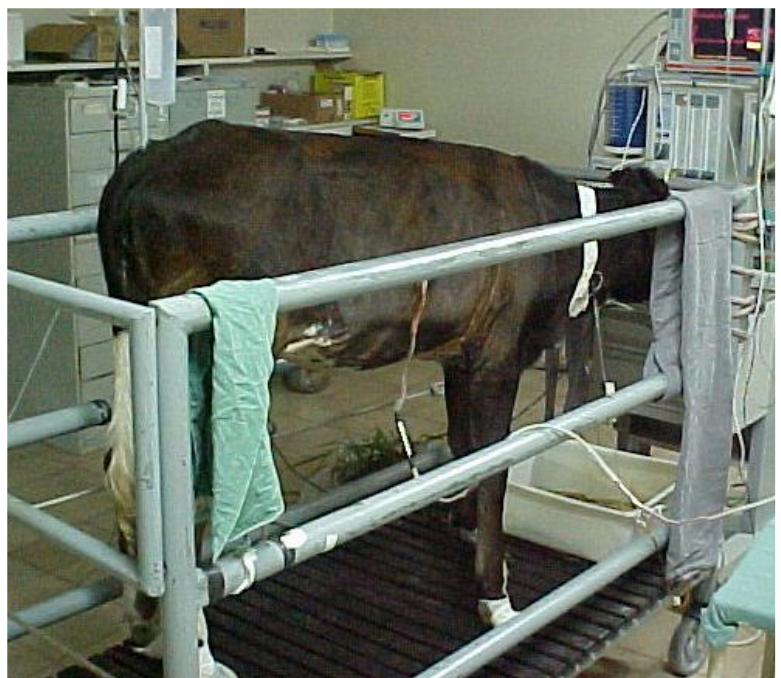

(b)

Figure 1. (a) IDPC researchers group (b) ATAH “in vivo" experiments in calves as LVAD.

The group was struggling to keep up with the development of pulsatile devices and was losing the fight. In certain way, Brazil had been following several technologies with a few years' delay, manufacturing roller pumps, blood oxygenators, various types of valves, pacemakers and cardioverters. But, in the case of VADs, even today, although with economy and a competitive market, Brazil does not have a national manufacturer even though it had developed several technologies like Brushless Direct Current (BLDC) motors, high performance batteries, Transcutaneous Energy Transmission System (TETS), hydraulic or magnetic suspension, electronic controllers, cardiovascular simulators, biofunctional biomaterials and supervisory control logic. So, we decided that my master's topic would be a Centrifugal Flow Ventricular Assist Device (CFVAD), something new at that time in Brazil, and I would try a scholarship as visiting researcher in Prof. Nosé Lab at Baylor College of Medicine (BCM) in Houston. The year was 2005, everything was just an idea, but I knew that my life was going to change a lot. I just didn't know that I was going to meet the most incredible scientist I've ever met.

But this review paper is not about Prof. Nosé but the first Brazilian centrifugal ventricular assist device for long term mechanically assisted circulatory support. The first study and first publication to inaugurate this VAD idea was to make a conversion of a two days' antitraumatic pump (Phase 1) Spiral Pump (SP) to a 2 weeks' antithrombogenic pump (Phase 2) (3) and, after this step, the conversion of this device to a durable, implantable, and long-term blood pump (Phase 3)(10) Figure 2 shows the SP performance curves with different inlet ports. 
TAS Journal, vol. 5, n. 1, p. 01-12

ISSN: 2595-1521

MARCH 2021

eduardobock@gmail.com
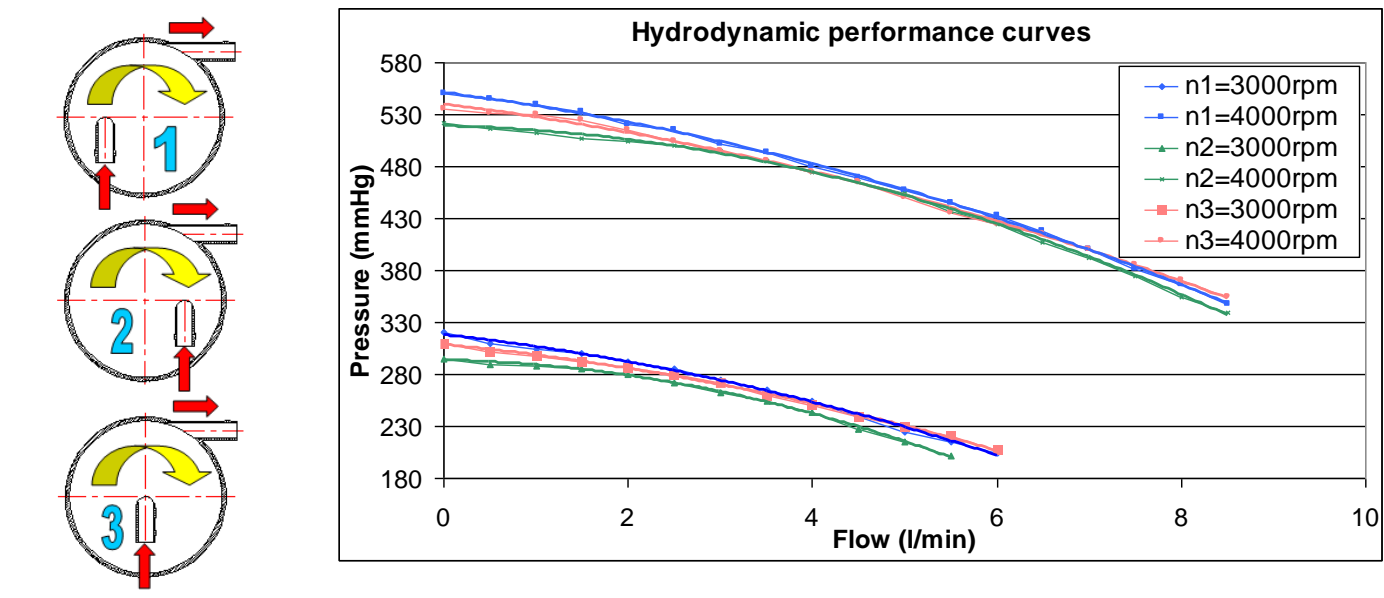

Figure 2. Comparison between three inlet ports. In red, the blood flow, in yellow, the impeller rotation of Spiral Pump.

Although obvious, this publication is actually a milestone for our group. The published study is a conversion of the concentric inlet of IDPC Spiral Pump (SP) Cardiopulmonary Bypass (CPB) pump to an eccentric inlet (10) required for the future ceramic bearings of our VAD that would only appear effectively in the following year. We count the first Brazilian centrifugal ventricular assist device conceiving in 2006, thus, turning 15 years now in 2021. At BCM, I started studying VADs and biotribology involved in ceramic pivot bearings that led me to visit Prof. Ryo Kosaka's group $(11,12)$, three different stages seen in Figure 3.

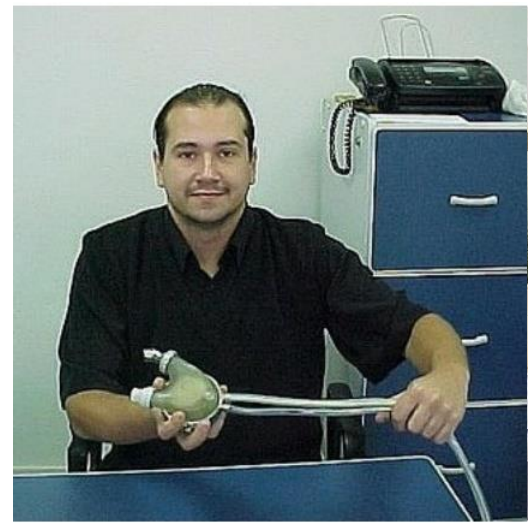

(a)

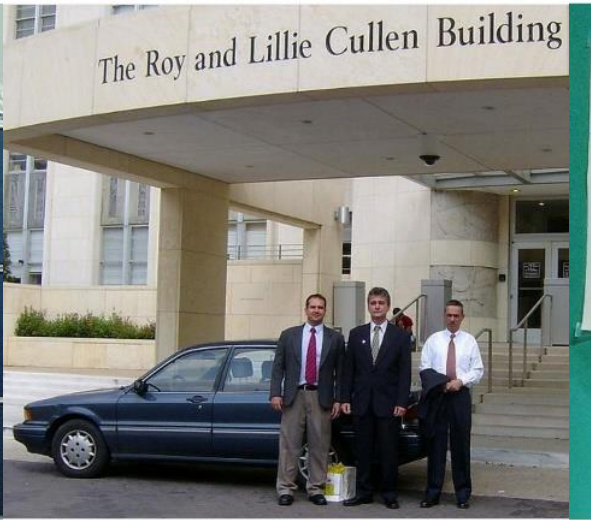

(b)

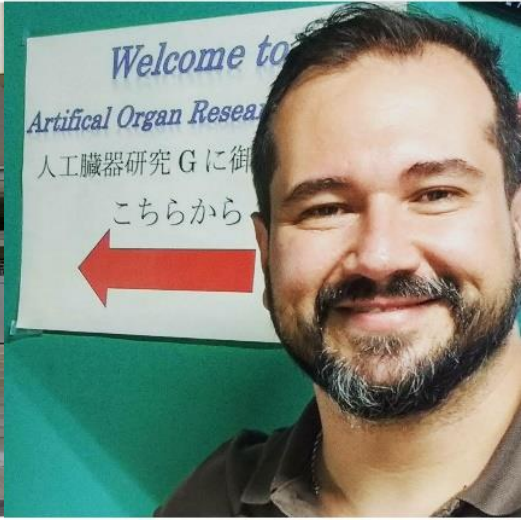

(c)

Figure 3. (a) In 2003 at IDPC, with the Auxiliary Total Artificial Heart project; (b) In 2006 at BCM, with Prof. Aron Andrade and Prof. Denys Nicolosi; and (c) In 2017, at AIST Tsukuba Japan. 
TAS Journal, vol. 5, n. 1, p. 01-12

ISSN: 2595-1521

MARCH 2021

eduardobock@gmail.com

Implantable Centrifugal Blood Pump (ICBP). Still in Brazil, talking to old machinists from the IDPC machine shop, many had already worked on centrifugal pump designs in the 1970s and 1980s. They described cable driven pumps and the famous Blackshear-Medtronics centrifugal pump (1969) that had a shaft and seal. It was nothing like what we wanted to do, or what was being done in Houston. We would be the first in Brazil and the second in the world.

Our inventiveness and boldness started by proposing a mixed flow rotor, a spiral cone and straight centrifugal vanes. Thus, the inlet stream would take advantage of an axial component and gradually convert the mixed flow to the centrifugal outlet at the end of the pump base. We hadn't even done the first mechanical design, nor the computer numerical simulations, and we were already defining the geometry. Or rather, we wanted to define initial parameters such as speed, volume, pressure and flow, so our range started with 2,000 RPM, $50 \mathrm{cc}\left(5.10^{-5} \mathrm{~m}^{3}\right), 100$ $\mathrm{mmHg}$, 5.0 L/min, Figure 4 (13).

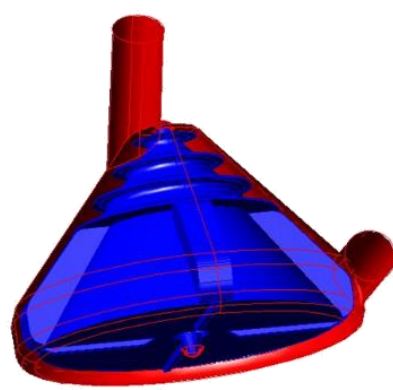

(a)

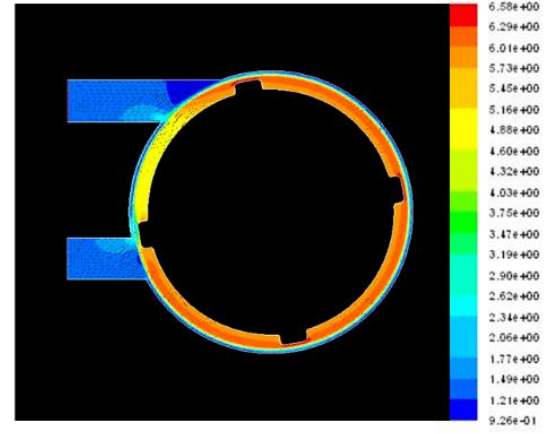

(b)

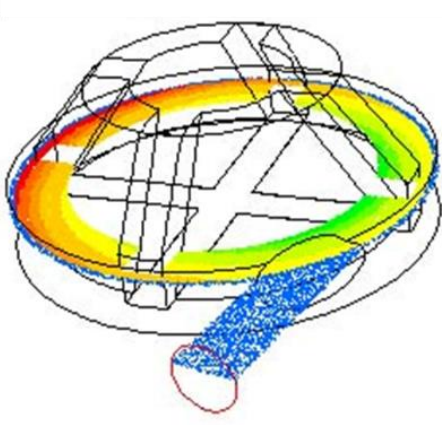

(c)

Figure (4). (a) Primitive three-dimensional conceptual design, (b) first two-dimensional numerical simulation and (c) three-dimensional flow with velocity distribution inside the pump.

It was defined that it would be a mixed flow pump (centrifugal + axial flow) with magnetic coupling and ceramic pivot bearings. The tribology pairs would need to be studied, the axis in $\mathrm{Al}_{2} \mathrm{O}_{3}$ (ceramic alumina with processes possibilities to be determined) and pivot in Ultra High Molecular Weight Polyethylene (UHMWPE) (in order to attenuate the vibration). The NIH Hemolysis tests according to ASTM F1840 would be performed with blood. Anatomical position tests in cadavers and animal experiments (6 pigs).

All set, we machined first pieces and assembled a first prototype just to get an idea of the proportions. The small pieces were glued in rotor and they eventually came loose as they were made of different materials like acrylic resin and Delrin, Figure 5. 


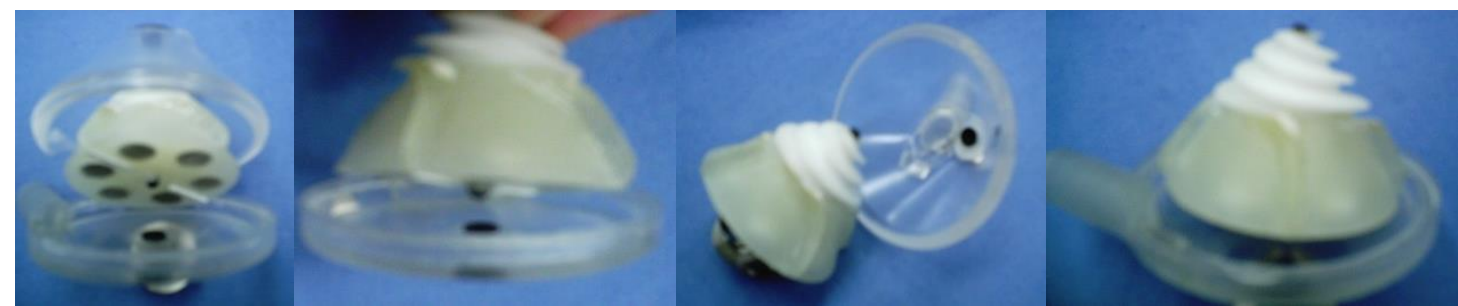

Figure 5. First prototype with rotor composed of two separate parts and vanes glued in different materials.

Since this approach presented results much lower than expected, the entire rotor was covered with white polyurethane resin, Figure 6. Not only this first prototype shown (Figure 5 and 6) with the rotor composed of glued parts without resin coating, as well as the model with improvements, proved to be amateur devices. They could serve as model for a casting mold, or even lost wax casting, but it was decided that the best strategy would be Computer Numerical Control (CNC) machining in a high speed 3-axis machining center.

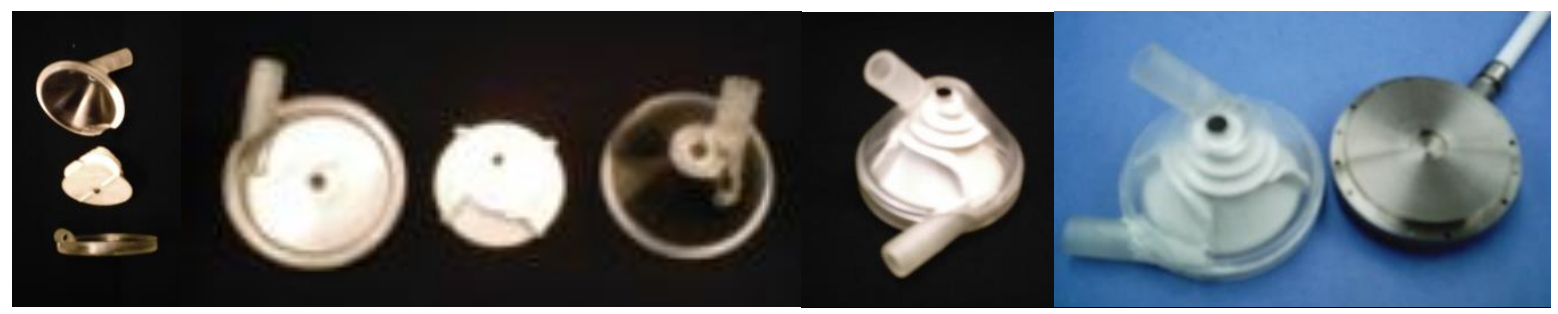

Figure 6. Second prototype: rotor covered with a white polyurethane resin.

Since this technology was not available in our laboratory in Brazil at that time, this was the last part of development before the BCM phase. With the approval of the CNPq research grant, I received a visiting researcher scholarship to begin studies in Houston in February 2006.

Biomaterials, Hemocompatibility and Computational Fluid Dynamics. Even with all the progress achieved, it is difficult to talk briefly about the three topics, which is why it is even more difficult to correlate the three, create a logical causal link and propose a wide VADs' development strategy. Much has already been achieved in this field of knowledge, as mentioned at the beginning of this paper, both in the prediction of hemolysis by Computational Fluid Dynamics (CFD), which was much more direct, but less exploratory (14-17). As for the knowledge of the blood interaction in turbulent flows, the mechanical trauma that is imposed to the wall of the red blood cells and how this can be quantified. Although there are still several methodologies and much to discover, the computational power and ease of validation of 
TAS Journal, vol. 5, n. 1, p. 01-12

ISSN: 2595-1521

MARCH 2021

eduardobock@gmail.com

mathematical models and numerical simulations gives modern VAD scientists a broad toolbox (18-25).

After this first phase of conception and three-dimensional design, the BCM group helped us with decades of knowledge in biomaterials research, in vitro tests and animal experimentation. But, especially, it helped us with personal financial support from Prof. Yukihiko Nosé (I will be eternally grateful for that), since the Brazilian grant did not cover costs with equipment and expenses with materials.

But this feature facilitated access to BCM's mechanical workshops and brought me closer to professionals who also had decades of experience in manufacturing processes such as Mr. Juan Fernandez, that helped me to obtain the best parameters for ceramic materials, the possibilities of machining green bodies, its characterization techniques, sintering and finishing, as well as the first tribological tests and evaluation of biomaterials in pivot bearings (26-32).

The issue of pivot bearings has always raised doubts about hemocompatibility and its feasibility, since its appearance in Gyro pump (2). But it became a consensus a long time ago when it made possible to support axial pumps impellers that, in the vast majority, appeared working with similar pivot bearings $(33,34)$. In the Brazilian CFVAD, we decided to call "support bearings" and the dual impeller Implantable Centrifugal Blood Pump (ICBP) device (35). The assay methodology following ASTM F1830 and ASTM F1841 for Normalized Index of Hemolysis (NIH) was done with the measurement of Plasma-Free Hemoglobin (PFH) by the Tetramethylbenzidine (TMB) method, but it was replicated in the future with Harboe method when we developed a new pump, recently (36).

Conclusions. After the prolific period as invited researcher at BCM, the IDPC group had a productive leap. The contact with researchers from the University of São Paulo (USP) generated FAPESP's first thematic project and each of the colleagues there had the opportunity to develop their own specific theme within the large project of this CFVAD. The project title even focused on the pump's propulsion system (37).

But the fact is that several parallel projects, within the IDPC, USP, and even in the Instituto Federal de São Paulo (IFSP) were born from that interaction, such as the electromagnetic suspension for a fourth generation of CFVADs (38-51).

Another important factor, which we can characterize as a paradigm shift in mechanical circulatory assistance is its size reduction due to the mechanical demand of pumps, which were previously designed to work in a range of 7-10 L/min with $120 \mathrm{mmHg}$ and nowadays are much smaller and provide only 3-5 L/min (52).

But a promising bet that could be made is that the future belongs to the peripheral countries in this technological race, such as Brazil, Russia, India, China and South Africa, which are large emerging economies of the BRICS bloc. These countries are the future for those who want to invest in VADs $(23,25,53-57)$. 
TAS Journal, vol. 5, n. 1, p. 01-12

ISSN: 2595-1521

MARCH 2021

eduardobock@gmail.com

Another important step for monitoring and evaluating the technologies involved in VADs is the Interagency Registry for Mechanically Assisted Circulatory Support (INTERMACS) (58). The fact of accumulating data between agencies makes it possible to analyze previously unknown parameters and search for correlations between therapies and clinical results on statistical basis, which, in the case of VADs, is often not significant. Future data mining and Internet of Things (IoT) tools will enable not only analysis but also the adjustment of control in real time through secure artificial intelligence.

I like to say that's when the Artificial Heart will meet the Artificial Intelligence...

Acknowledgments. The author gratefully acknowledges financial support from KIT, CAPES PGTPA 59/2014, CNPq and FAPESP Temático and PIPE for partially support his research. In addition, he wishes to thank the following those who made valuable suggestions or who have otherwise contributed to the preparation of the manuscript: Aron Andrade, Jeison Fonseca, Tarcisio Leão, Evandro Drigo, Breno Nishida, Marcelo Barboza, José Ricardo Sousa Sobrinho and Bruno Santos.

Disclosure. The author reports no conflicts of interest in this work.

\section{References.}

1. Nosé Y, Schauman M, Kantrowitz A. Experimental use of an electronically controlled prosthesis as an auxiliary left ventricle. Trans Am Soc Artif Intern Organs. 1963;IX:26974.

2. Yoshikawa M, Nonaka K, Linneweber J, Kawahito S, Ohtsuka G, Nakata K ichi, et al. Development of the NEDO implantable ventricular assist device with Gyro centrifugal pump. Artif Organs. 2000;24(6):459-67.

3. Nosé Y. Design and Development Strategy for the Rotary Blood Pump. Artif Organs. 1998 Jun 4;22(6):438-46.

4. Dohmen PM, Laube H, Jonge K De, Baumann G, Konertz W. Mechanical circulatory support for one thousand days or more with the NOVACOR N100 Left Ventricular Assist Device. J Thorac Cardiovasc Surg. 1995;117(5):1029-30.

5. Koul B, Solem JO, Steen S, Casimir-Ahn H, Granfeldt H, Lönn UJ. HeartMate left ventricular assist device as bridge to heart transplantation. Ann Thorac Surg. 1998;65(6):1625-30.

6. Burton NA, Lefrak EA, Macmanus Q, Hill A, Marino JA, Speir AM, et al. A reliable bridge to cardiac transplantation: The TCI left ventricular assist device. Ann Thorac Surg 1993;55(6):1425-31.

7. Farrar DJ, Hill JD, Pennington DG, McBride LR, Holman WL, Kormos RL, et al. Preoperative and postoperative comparison of patients with univentricular and biventricular support with the thoratec ventricular assist device as a bridge to cardiac 
TAS Journal, vol. 5, n. 1, p. 01-12

ISSN: 2595-1521

MARCH 2021

eduardobock@gmail.com

transplantation. J Thorac Cardiovasc Surg. 1997;113(1):202-9.

8. Holman WL, Skinner JL, Waites KB, Benza RL, McGiffin DC, Kirklin JK. Infection during circulatory support with ventricular assist devices. Ann Thorac Surg. 1999;68(2):711-6.

9. Andrade A, Nicolosi D, Lucchi J, Biscegli J, Arruda ACF, Ohashi Y, et al. Auxiliary total artificial heart: A compact electromechanical artificial heart working simultaneously with the natural heart. Artif Organs. 1999;23(9):876-80.

10. Bock EGP, de Andrade AJP, Wada EAE, da Fonseca JWG, Leme J, Nicolosi DEC, et al. A new concept of centrifugal blood pump using pivot bearing system: the conversion of the Spiral Pump inlet port. Technol Meets Surg Int São Paulo, SP, 4p. 2005;(1998):2-5.

11. Kosaka R, Maruyama O, Nishida M, Yada T, Saito S, Hirai S, et al. Improvement of Hemocompatibility in Centrifugal Blood Pump With Hydrodynamic Bearings and Semiopen Impeller : In Vitro Evaluation. 2009;33(10):798-804.

12. Kosaka R, Sakota D, Nishida M, Maruyama O, Yamane T. Improvement of hemolysis performance in a hydrodynamically levitated centrifugal blood pump by optimizing a shroud size. J Artif Organs. 2021;24(2):157-63.

13. Bock E, Andrade A, Nicolosi D, Biscegli JF, Fonseca J, Arruda AC. Hydrodynamic characteristics applied in determination of the new inlet port's angle from a Centrifugal Blood Pump. Asaio J. 2006;52(2):63A.

14. Legendre D, Antunes P, Bock E, Andrade A, Biscegli JF, Ortiz JP. Computational fluid dynamics investigation of a centrifugal blood pump. Artif Organs. 2008;32(4):342-8.

15. Song X, Wood HG, Olsen D. Computational fluid dynamics (CFD) study of the 4th generation prototype of a continuous flow ventricular assist device (VAD). J Biomech Eng. 2004;126(2):180-7.

16. Throckmorton AL, Untaroiu A, Lim DS, Wood HG, Allaire PE. Fluid force predictions and experimental measurements for a magnetically levitated pediatric ventricular assist device. Artif Organs. 2007;31(5):359-68.

17. Paul R, Apel J, Klaus S, Schügner F, Schwindke P, Reul H. Shear stress related blood damage in laminar Couette flow. Artif Organs. 2003;27(6):517-29.

18. Faghih MM, Keith Sharp M. Extending the Power-Law Hemolysis Model to Complex Flows. J Biomech Eng. 2016;138(12):6-9.

19. Mack E, Untaroiu A. Hemodynamics Characteristics of a Four-Way Right-Atrium Bypass Connector. J Fluids Eng. 2018;140(12):121106.

20. Chen Z, Jena SK, Giridharan GA, Sobieski MA, Koenig SC, Slaughter MS, et al. Shear stress and blood trauma under constant and pulse-modulated speed CF-VAD operations: CFD analysis of the HVAD. Med Biol Eng Comput. 2019;57(4):807-18.

21. Wang S, Tan J, Yu Z. Comparison and experimental validation of turbulence models for an axial flow blood pump. J Mech Med Biol. 2019;19(8):1-14.

22. Li H, Gou Z, Huang F, Ruan X dong, Qian W wei, Fu X. Evaluation of the hemolysis and fluid dynamics of a ventricular assist device under the pulsatile flow condition. $\mathbf{J}$

Hydrodyn. 2019;31(5):965-75.

23. Denisov M V., Telyshev D V., Selishchev S V., Romanova AN. Investigation of 
TAS Journal, vol. 5, n. 1, p. 01-12

ISSN: 2595-1521

MARCH 2021

eduardobock@gmail.com

Hemocompatibility of Rotary Blood Pumps: The Case of the Sputnik Ventricular Assist Device. Biomed Eng (NY). 2019;53(3):181-4.

24. Shida S, Masuzawa T, Osa M. Dynamic motion analysis of impeller for the development of real-time flow rate estimations of a ventricular assist device. Int J Artif Organs. 2020;18 .

25. Telyshev D, Denisov M, Markov A, Fresiello L, Verbelen T, Selishchev S. Energetics of blood flow in Fontan circulation under VAD support. Artif Organs. 2020;44(1):50-7.

26. Ortega FS, PiIeggi RG, Sepulveda P, Pandolfelli VC. Optimizing particle packing in powder consolidation. Am Ceram Soc Bull. 1999;78(8):106-11.

27. Bonetti LF, Capote G, Santos L V., Corat EJ, Trava-Airoldi VJ. Adhesion studies of diamond-like carbon films deposited on Ti6Al4V substrate with a silicon interlayer. Thin Solid Films. 2006 Sep 25;515(1):375-9.

28. Montanheiro TLDA, Cristóvan FH, Machado JPB, Tada DB, Durán N, Lemes AP. Effect of MWCNT functionalization on thermal and electrical properties of PHBV/MWCNT nanocomposites. J Mater Res. 2014;30(1):55-65.

29. Carvalho CN, Grazziotin-Soares R, De Miranda Candeiro GT, Martinez LG, De Souza JP, Oliveira PS, et al. Micro push-out bond strength and bioactivity analysis of a bioceramic root canal sealer. Iran Endod J. 2017;12(3):343-8.

30. Hernandes MMAP, Da Rocha JAF, Saito MA, Araki SY, Silva P, Stoeterau RL, et al. Dimensional control in pre-sintered Zirconia machining for Double Pivot Micro Bearings of blood pumps. In: Proceedings of the 17th International Conference of the European Society for Precision Engineering and Nanotechnology, EUSPEN 2017. 2017.

31. Benalcázar Jalkh EB, Bergamo ETP, Monteiro KN, Cesar PF, Genova LA, Lopes ACO, et al. Aging resistance of an experimental zirconia-toughened alumina composite for large span dental prostheses: Optical and mechanical characterization. J Mech Behav Biomed Mater. 2020 Apr 1;104:103659.

32. Momesso GAC, Polo TOB, da Silva WPP, Barbosa S, Freitas GP, Lopes HB, et al. Miniplates coated by plasma electrolytic oxidation improve bone healing of simulated femoral fractures on low bone mineral density rats. Mater Sci Eng C. 2021 Jan $1 ; 120: 111775$.

33. Osa M, Masuzawa T, Saito T, Tatsumi E.

した小児用人工心臓循環補助時の外乱力推定と磁気浮上特性評価. 2018;26(1):95101.

34. Kubrusly LF, Martins F, Savytzky S, Wollman D, Adam R, Bairro FR De, et al. Dispositivo de assistência circulatória mecânica intraventricular de fluxo axial : estudo in vitro. 2000;15(2):169-72.

35. Bock E, Ribeiro A, Silva M, Antunes P, Fonseca J, Legendre D, et al. New centrifugal blood pump with dual impeller and double pivot bearing system: Wear evaluation in bearing system, performance tests, and preliminary hemolysis tests. Artif Organs. 2008;32(4):329-33.

36. Hernandes MMAP, Drigo E, Souza LF, Nishida BYT, Bock EGP, Andrade AJP, et al. Velocimetria Computacional por Imagens de Partículas versus análise numérica de 
TAS Journal, vol. 5, n. 1, p. 01-12

ISSN: 2595-1521

MARCH 2021

eduardobock@gmail.com

escoamento em um Dispositivo de Assistência Ventricular. Acad Soc J. 2017;1(2):93-9.

37. Souza RL, Chabu IE, Drigo da Silva E, Andrade AJP, Leao TF, Bock EGP. A strategy for designing of customized electromechanical actuators of blood pumps. Artif Organs. 2020 Aug 15;44(8):797-802.

38. Horikawa O, de Andrade A, Bock E, da Silva I, Lee AEM, Fernandes CAF, et al. Study on a magnetic suspension of the rotor of an artificial heart. In: Proc ABCM Symp Ser Mechatronics. 2008. p. 562-70.

39. Ibrahim RC, Sakai T, Nishida T, Horiuchi T, Shiosaki T, Matsushige K. Characterization of niobium-doped lead titanate thin films. Japanese J Appl Physics, Part 1 Regul Pap Short Notes Rev Pap. 1996 Sep 1;35(9 SUPPL. B):4995-8.

40. Pai CN, Shinshi T, Asama J, Takatani S. Development of a Compact Maglev Centrifugal Blood Pump Enclosed in a Titanium Housing. 2008;2(3):343-55.

41. da Silva I, Horikawa O, Cardoso JR, Camargo FA, Andrade AJP, Bock EGP. Single axis controlled hybrid magnetic bearing for left ventricular assist device: Hybrid core and closed magnetic circuit. Artif Organs. 2011;35(5):448-53.

42. Biselli B, Ayub-Ferreira SM, Avila MS, Gaiotto FA, Jatene FB, Bocchi EA. Left ventricular assist device followed by heart transplantation. Arq Bras Cardiol. 2015;104(3):e22-4.

43. Galantini D, Rocha J, Bock E. Total Artificial Heart (TAH): preliminary results in vitro. Int J Artif Organs. 2017;40(8):453.

44. Costa MC, Nabeta SI, Cardoso JR. Modified nodal analysis applied to electric circuits coupled with FEM in the simulation of a universal motor. IEEE Trans Magn. 2000;36:1426-30.

45. Dinkhuysen JJ, Andrade A, Conteras C, Paulista PP, Leme J, Manrique R. Experimental study of pulsatile implantable electromechanical artificial ventricle. Rev Bras Cir Cardiovasc. 2011;26(1):76-85.

46. Bora TC, Coelho LDS, Lebensztajn L. Bat-inspired optimization approach for the brushless DC wheel motor problem. In: IEEE Transactions on Magnetics. 2012. p. 94750 .

47. De Camargos AFP, Silva VC, Guichon JM, Munier G. Efficient parallel preconditioned conjugate gradient solver on GPU for FE modeling of electromagnetic fields in highly dissipative media. IEEE Trans Magn. 2014;50(2):569-72.

48. Vatanabe SL, Lippi TN, Lima CR d., Paulino GH, Silva ECN. Topology optimization with manufacturing constraints: A unified projection-based approach. Adv Eng Softw. 2016 Oct 1;100:97-112.

49. Li Z, Tavernier F, Bréard A, Krähenbühl L, Li Z, Tavernier F, et al. Utilisation d'informations géométriques a priori pour améliorer l'identification du champ H mesuré autour d'un dispositif. In: Numélec. 2017.

50. T. Veiga J, A. O. Pessoa M, Junqueira F, E. Miyagi P, J. dos Santos Filho D. Controle de Sistemas de Manufatura Distribuídos no contexto da Indústria 4.0. In: Congresso Brasileiro de Automática - CBA. Sociedade Brasileira de Automatica; 2020.

51. Coda FA, Santos Filho DJ, Junqueira F, Miyagi PE. Big Data Acquisition Architecture: 
TAS Journal, vol. 5, n. 1, p. 01-12

ISSN: 2595-1521

MARCH 2021

eduardobock@gmail.com

An Industry 4.0 Approach. In: IFIP Advances in Information and Communication Technology. Springer; 2020. p. 222-9.

52. Ayub-Ferreira SM, De Souza Neto JD, Almeida DR, Biselli B, Avila MS, Colafranceschi AS, et al. Mechanical circulatory support guideline of the Brazilian Society of Cardiology. Arq Bras Cardiol. 2016 Aug 1;107(2):1-33.

53. Petukhov DS, Selishchev S V., Telyshev D V. Total Artificial Heart: State-of-the-art. Biomed Eng (NY). 2015;49(4):193-6.

54. Wu Y, Zhu L fan, Luo Y. Development and current clinical application of ventricular assist devices in China. J Zhejiang Univ Sci B. 2017;18(11):934-45.

55. Zhu L, Wu Y, Luo Y. Experimental evaluation of a novel injection suspended impeller for implantable centrifugal blood pump. In: International Journal of Applied Electromagnetics and Mechanics. IOS Press; 2016. p. 525-30.

56. $\mathrm{Fu} \mathrm{Y,} \mathrm{Hu} \mathrm{L,} \mathrm{Ruan} \mathrm{X,} \mathrm{Fu} \mathrm{X.} \mathrm{A} \mathrm{transcutaneous} \mathrm{energy} \mathrm{transmission} \mathrm{system} \mathrm{for} \mathrm{artificial}$ heart adapting to changing impedance. Artif Organs. 2015 Apr 1;39(4):378-87.

57. Zhang Q, Gao B, Gu K, Chang Y, Xu J. The study on hemodynamic effect of varied support models of BJUT-II VAD on coronary artery: a primary CFD study. Asaio J. 2014;60(6):643-51.

58. Molina EJ, Shah P, Kiernan MS, Cornwell WK, Copeland H, Takeda K, et al. The Society of Thoracic Surgeons Intermacs 2020 Annual Report. Ann Thorac Surg. 2021;111(3):778-92. 